\title{
Antifungal Activities of Ageratum conyzoides L. Extract against Rice Pathogens Pyricularia oryzae Cavara and Rhizoctonia solani Kühn
}

\author{
Cuong C. Nguyen ${ }^{1,2}$, Thanh Q. C. Nguyen ${ }^{1,3}{ }^{\mathbb{D}}$, Kenji Kanaori ${ }^{1}$, Tran Duy Binh ${ }^{1} \mathbb{D}^{\mathbb{D}}$, Xuyen H. T. Dao $^{2}$, \\ Le Van Vang ${ }^{2}$ and Kaeko Kamei ${ }^{1, * \mathbb{D}}$
}

1 Department of Functional Chemistry, Kyoto Institute of Technology, Kyoto 606-8585, Japan; chicuong@ctu.edu.vn (C.C.N.); nqcthanh@ctu.edu.vn (T.Q.C.N.); kanaori@kit.ac.jp (K.K.); tdbinh22@gmail.com (T.D.B.)

2 Department of Plant Protection, College of Agriculture, Can Tho University, Can Tho City 900000, Vietnam; dthxuyen@ctu.edu.vn (X.H.T.D.); lvvang@ctu.edu.vn (L.V.V.)

3 Department of Chemistry, College of Natural Sciences, Can Tho University, Can Tho City 900000, Vietnam

* Correspondence: kame@kit.ac.jp; Tel./Fax: +81-75-724-7753

Citation: Nguyen, C.C.; Nguyen, T.Q.C.; Kanaori, K.; Binh, T.D.; Dao, X.H.T.; Vang, L.V.; Kamei, K. Antifungal Activities of Ageratum conyzoides L. Extract against Rice Pathogens Pyricularia oryzae Cavara and Rhizoctonia solani Kühn. Agriculture 2021, 11, 1169. https:// doi.org/10.3390/agriculture11111169

Academic Editors: Eugenio Llorens, Begonya Vicedo, Loredana Scalschi and Carlos Agustí-Brisach

Received: 27 October 2021 Accepted: 17 November 2021 Published: 19 November 2021

Publisher's Note: MDPI stays neutral with regard to jurisdictional claims in published maps and institutional affiliations.

Copyright: (c) 2021 by the authors. Licensee MDPI, Basel, Switzerland. This article is an open access article distributed under the terms and conditions of the Creative Commons Attribution (CC BY) license (https:// creativecommons.org/licenses/by/ $4.0 /)$.

\begin{abstract}
Blast disease and sheath blight disease caused by infection with Pyricularia oryzae and Rhizoctonia solani, respectively, are serious fungal diseases in paddy fields. Although synthetic fungicides have been used to control these diseases, the development of ecologically friendly alternatives is required because fungicides can cause health problems and environmental pollution. Natural herbs possessing antifungal activities are among the candidates as alternatives. Ageratum conyzoides is known to contain antifungal compounds, such as precocene II and polymethoxyflavones. Here, we report the antifungal activities of five compounds isolated after ethanol extraction from Ageratum conyzoides against Pyricularia oryzae and Rhizoctonia solani in vitro. Further, we demonstrated the protective effect of the extract on rice from Pyricularia oryzae infection by field trial testing in a shaded net-house.
\end{abstract}

Keywords: antifungal; alternative antimicrobials; plant extracts; Ageratum conyzoides; rice pathogen; Pyricularia oryzae; Rhizoctonia solani

\section{Introduction}

The rice (Oryza sativa L.) plant is an essential cereal crop [1,2] grown mainly in Asia [3,4]. The rice crop is affected by various diseases caused by fungi, bacteria, viruses, mycoplasma-like organisms, and nematodes [5-7]. Two kinds of fungi, rice blast (Pyricularia oryzae Cavara) and sheath blight (Rhizoctonia solani Kühn), are generally considered as the principal rice pathogenic agents because of their widespread distribution and destructiveness $[5,7,8]$.

P. oryzae infects all rice plant parts, such as the leaf, collar, node, internodes, neck, and other parts of the panicle, at different growth periods $[5,7,9]$. It sometimes occurs in the leaf sheath, but neck blast and panicle blast are the most damaging stages of the disease $[5,8,10]$. The symptomatic lesion of rice leaves is gray or whitish at the center and has a brown border and an elliptical shape [5,7]. Under favorable weather conditions for the pathogen, conidia are produced on lesions and dispersed by wind and rain splash to reinitiate the infection cycle [5,7]. This causes annual yield losses of approximately $10 \%-30 \%$ in various rice-producing regions [11].

$R$. solani is a fungal pathogen with a wide range of hosts, including rice, wheat, soybean, and corn $[5,7,12,13]$. Initial symptoms of infection with this pathogen usually develop on the leaf sheaths or just above the waterline as circular, oval, or ellipsoid watersoaked spots that are greenish-gray in color. The transport of nutrients and water is blocked, resulting in physiological impairment in which the infected leaves dry out, and 
the rice plant dies. In severe cases, lodging and tillers may collapse, causing enormous economic losses $[5,7,13]$. This can cause a rice yield loss of up to $40 \%$ when the disease is severe [14]. To control fungal diseases in agriculture, several management methods, such as the use of fungicides or natural antifungals, development of resistant cultivars, and biocontrol and control of nitrogen fertilizer, can be applied $[5,7,9,11,15-17]$. Chemical agents, including fungicides, are widely used in the field [5,7,9]. However, they are hazardous to the environment, human health, and beneficial predators $[11,16,18]$. In a case study, it has been reported that the extreme use of antibiotics in agricultural fields or direct human consumption of the products through daily meals led to the generation of antibiotic-resistant fungi with serious consequences such as cancer, liver damage, and kidney failure [19]. The extensive use of antibiotics in agriculture has resulted in the emergence of multidrug-resistant bacteria [20]. It has been suggested that the application of fungicides in agriculture should be strictly regulated to ensure the toxicological safety of commercialized foods and pose negligible risks of acute toxicity due to carryover. The use of a mixture of antifungals with different action mechanisms is encouraged to decrease the development of drug resistance in fungi [21]. Therefore, the search for new antimicrobials is required to develop a cocktail of antifungals with different mechanisms and for designing new fungicides.

In contrast, natural antifungal products are considered to be more environmentally friendly and effective alternatives to fungicides in sustainable agricultural systems $[11,15,22,23]$. For application as alternative agents in agriculture, plant extracts and/or antimicrobial components have been studied in vitro and in vivo. Naqvi et al. showed that the water extracts of various plants suppressed bacterial blight disease caused by Xanthomonas oryzae pv. oryzae on rice in greenhouses and also improved agronomic traits such as plant height, panicle length, number of tillers and grains/panicle, grain weight, and yield [24]. Another group reported that three plant aqueous extracts enhance seed germination and seedling vigor [25] and also showed that plant extracts suppress bacterial blight disease of rice in greenhouses and Adhatoda vasica leaf extract induces accumulation of defense enzymes, which can be associated with the induction of resistance against infectious diseases. Azadirachta indica seed extracts reduced the in vitro radial growth of P. oryzae and suppressed the development and spread of blast disease in rice plants in a greenhouse [26]. These reports suggest that plant extracts, including waste, might have no negative impact on the growth of agricultural plants. Moreover, plant extracts have been used for medicinal and antimicrobial purposes since ancient times $[27,28]$. Therefore, they are being developed as a new source of farming chemicals with antimicrobial and insecticidal properties against plant pathogens, including viruses, fungi, bacteria, nematodes, and insects, in vitro and in vivo $[15,27,29-33]$. In contrast, Yang et al. pointed out that fungicides can directly affect nontarget organisms, including beneficial microorganisms, if fungicides act on their identical or similar mechanisms and constituents with targeting fungi [34]. This prompted us to study the application of plant extracts or their antifungal components in the agricultural field, although we need to consider the effect on beneficial microorganisms.

Ageratum conyzoides L., belonging to the Asteraceae family, is native to tropical America and is now growing worldwide. It grows in cultivated fields of sugarcane and other crops, along roadsides, and in backyard gardens. In some countries, this herb is used as a folk medicine to treat conditions such as purgative, febrifuge, ophthalmia, colic, ulcers, and wounds [27,32,35]. It is also used against insect and plant diseases [27]. A. conyzoides has been used to isolate alkaloids, coumarins, flavonoids, chromenes, benzofurans, sterols, and terpenoids $[27,32,36]$. A. conyzoides is also known to contain antifungal compounds, such as precocene II and polymethoxy flavones. A. conyzoides extracts have been used in medicine and agriculture $[32,33,37,38]$. However, evidence of antifungal activities of the extracts and isolated compounds against blast disease and sheath blight disease has not been reported.

This study aimed to examine the antifungal properties of $A$. conyzoides ethanol extract as a natural antifungal source to control infectious diseases in rice. We isolated five compounds from the extract that showed antifungal activity against $P$. oryzae and $R$. solani 
in vitro. Furthermore, we investigated the protective effect of $A$. conyzoides ethanol extract on rice from $P$. oryzae infection in a shaded net-house.

\section{Materials and Methods}

\subsection{Materials and General Methods}

The aerial parts of A. conyzoides were collected from an orchard in Phu Thuan Village, Phu Thinh Ward, Tam Binh District, Vinh Long Province, Vietnam (10.13163 N, 105.88936 E), from March to April 2018. The plant was identified by Professor Tran Vu Phen and kept in the Department of Plant Protection, Can Tho University, with the code number CCH-10.

Solvents used for extraction, solvent partition and chromatography, and dimethyl sulfoxide (DMSO) were of special grade and were obtained from Fujifilm Wako Chemicals (Osaka, Japan). Silica gel 60 (0.040-0.063 mm, 230-400 mesh ASTM), silica gel 60 F254, and aluminum thin-layer chromatography (TLC) plates were purchased from Merck KGaA (Darmstadt, Germany). A silica gel column $(3.5 \times 60 \mathrm{~cm})$ was equilibrated with hexane and eluted by increasing the concentration of ethyl acetate in hexane. Reversed-phase chromatography was performed using an HPLC system with Pump L-2130 and a UVVIS detector L-2420 (Hitachi, Tokyo, Japan). A Develosil ODS-5 column $(4.6 \times 150 \mathrm{~mm}$; Nomura Chemical Co. Ltd., Aichi, Japan) was used. Antifungal compounds were eluted with a 70 min linear gradient from $5 \%$ acetonitrile to $90 \%$ acetonitrile at a flow rate of $1 \mathrm{~mL} \cdot \mathrm{min}^{-1}$ and detected by measuring absorption at $270 \mathrm{~nm}$. The purities of the antifungal compounds were checked by TLC using silica gel 60 F254 plates. After developing with a mixture of hexane and EtOAc, the TLC plate was soaked in sodium phosphomolybdate in vitro n-hydrate solution (PMA, Fujifilm Wako Chemicals, Osaka, Japan) for $2 \mathrm{~s}$ and then heated for $2 \mathrm{~min}$ at $95^{\circ} \mathrm{C}$ for visualization.

P. oryzae Cavara (MAFF 101512) and R. solani RLS1 (MAFF 243449) used for in vitro antifungal assays were obtained from the GenBank Project, National Agriculture and Food Research Organization, Japan. P. oryzae used in the field trial test was obtained from the Cuu Long Delta Rice Research Institute (CLDRRI), Vietnam. Potato dextrose agar (PDA) and potato dextrose broth (PDB) were purchased from Nissui (Tokyo, Japan).

\subsection{Extraction and Solvent Partition of A. conyzoides}

The aerial parts of $A$. conyzoides were thoroughly washed with tap water, cut into small pieces, and air-dried for seven days under net-house conditions. The raw materials were ground to make a fine powder $(1.2 \mathrm{~kg})$ and then extracted in $12 \mathrm{~L}$ of ethanol at $25^{\circ} \mathrm{C}$ for $24 \mathrm{~h}$. The supernatant was collected using filtration paper (Advantec, No. 1, Japan) and then evaporated in a vacuum rotary evaporator (Iwaki, Tokyo, Japan). This procedure was repeated six times. Finally, $97.8 \mathrm{~g}$ of $A$. conyzoides ethanol extract (ACE) was obtained. ACE was suspended in water $(200 \mathrm{~mL})$, followed by the subsequent partitioning of hexane (3.5 L), chloroform (3.2 L), and EtOAc (3 L). The yields of fractions after lyophilization for hexane (ACE-hexane), chloroform (ACE-chloroform), EtOAc (ACE-EtOAc), and water (ACE-water) were $27.4,26.5,4.4$, and $25.5 \mathrm{~g}$, respectively.

\subsection{Isolation of Antifungal Compounds from $A C E$}

ACE-hexane ( $20 \mathrm{~g}$ ) was subjected to a silica gel column, and the fraction eluted by a mixture of hexane and EtOAc at a ratio of 25:1 was further separated using silica gel chromatography twice and then by reversed-phase chromatography. Finally, antifungal compound $1(55.3 \mathrm{mg})$ was obtained. The fraction eluted with a mixture of hexane and EtOAc at a ratio of 50:1 was separated using silica gel chromatography twice, followed by reversed-phase chromatography. Finally, three antifungal compounds $(2,3$, and 4$)$ were obtained. The yields of compounds 2, 3, and 4 were $60.3,30.2$, and $26.7 \mathrm{mg}$, respectively.

ACE-chloroform ( $15 \mathrm{~g}$ ) was separated by silica gel column chromatography. The fraction eluted with a mixture of hexane and EtOAc at a ratio of 1:1 was used for further separation via reversed-phase chromatography. Finally, one final antifungal compound, 5, was isolated with a yield of $10.2 \mathrm{mg}$. 


\subsection{Assay for Inhibitory Activities against Mycelial Growth of P. oryzae and R. solani In Vitro}

A poisoned food assay was used to examine the antifungal activity of the isolated compounds. Briefly, P. oryzae and R. solani were cultured on PDA medium ( $39 \mathrm{~g}$ in $1 \mathrm{~L}$ of water) at $26^{\circ} \mathrm{C}$. To prepare the stock solutions, ACE and fractions obtained via solvent partition $(1000 \mathrm{mg}$ ) were dissolved in $2 \mathrm{~mL}$ of DMSO, or $20 \mathrm{mg}$ of the isolated compound was dissolved in a mixture of $200 \mu \mathrm{L} \mathrm{DMSO}$ and $200 \mu \mathrm{L}$ methanol. The stock solutions were serially diluted with PDB and mixed with PDA at $55^{\circ} \mathrm{C}$. The final DMSO concentration in PDA was maintained at $0.2 \%$, and the DMSO and methanol mixture was maintained at $0.2 \%$ for each component. The PDA-containing sample was then poured into a petri dish ( 3.5 or $8.6 \mathrm{~cm}$ diameter). After solidification, the mycelium plug ( 4 or $6 \mathrm{~mm}$ in diameter) of $P$. oryzae ( 5 days old) or $R$. solani ( 2 days old) was placed at the center of the dish. After incubation for various periods of time (specified in the figure legends) at $26^{\circ} \mathrm{C}$, the diameter $(\mathrm{mm})$ of radial mycelia was measured. The antifungal activity of the ACE sample was calculated in terms of percent inhibition (PI) of radial growth according to the following equation [39]:

$$
\mathrm{PI}(\%)=(\mathrm{DC}-\mathrm{DT}) / \mathrm{DC} \times 100
$$

where DC is the average diameter of radial mycelia treated without a sample (negative control), and DT is the average diameter of radial mycelia treated with the ACE sample.

The antifungal activity of the isolated compound was expressed as the half-maximal inhibitory concentration $\left(\mathrm{IC}_{50}\right)$, which is the concentration of the antifungal compound required to suppress the radial growth of fungi by $50 \%$.

\subsection{Identification of Antifungal Compounds}

The chemical structures of the isolated antifungal compounds were identified using a combination of multistage mass spectroscopy (MS) and one-dimensional (1D and 2D) NMR spectroscopy. The electrospray ionization time-of-flight (ESI-TOF) MS spectra were measured using a Bruker micrOTOF spectrometer, and all the ${ }^{1} \mathrm{H}$ and ${ }^{13} \mathrm{C}$ NMR spectra were recorded using a Bruker AV-600 spectrometer.

\subsection{Field Trial Test for ACE on Suppressing Rice Blast Disease}

P. oryzae was cultured on PDA at $28^{\circ} \mathrm{C}$ in the dark for four days. Thereafter, the fungus was kept at $28^{\circ} \mathrm{C}$ with a $12 \mathrm{~h}$ cycle of alternating dark and light conditions to stimulate sporulation. After 14 days, fungal spores were collected by gently scraping the medium with $5 \mathrm{~mL}$ of distilled water per dish and filtering with filter paper. The spore suspension was diluted with $0.01 \%$ Tween 20 to the required density $\left(10^{5}\right.$ spores $\left./ \mathrm{mL}\right)$.

Five seeds of the rice variety, Jasmine 85 (CLDRRI), were sown on the soil (1.5 kg dried weight / pot) taken from the top layer $(0-30 \mathrm{~cm})$ of a rice field in a plastic pot $(13 \times$ $7 \times 10 \mathrm{~cm}$ ). At 18 days after sowing, we marked the fifth leaf (complete leaf), and then $10 \mathrm{~mL}$ of spore suspension of $P$. oryzae was sprayed onto the whole plant. The pots were kept for $24 \mathrm{~h}$ in the dark at approximately $98 \%$ humidity and $25^{\circ} \mathrm{C}$ and were transferred to a greenhouse and maintained at regular humidity for development of the disease. Two days later ( $48 \mathrm{~h}$ after inoculation), the rice plants were sprayed with $10 \mathrm{~mL}$ of an ACE per pot $(2 \mathrm{mg} / \mathrm{mL}$ in $0.2 \% \mathrm{DMSO})$, tricyclazole $(0.625 \mathrm{mg} / \mathrm{mL}$ in water, Beam $75 \mathrm{WP}$, Dow AgroSciences, Indianapolis, IN, USA) as a positive control, or DMSO $(0.2 \%)$ as a negative control. The experiment was performed using a completely randomized design with four replicates.

At 5, 10, and 15 days after spraying ACE onto the whole rice plant, the symptoms on the marked leaf were recorded according to the rating scale of the International Rice Research Institute [40] with minor modifications. Disease levels were classified based on the damaged area (\%) in leaves: scale 0 , no damage; scale $1,<5 \%$; scale 3, 5-24\%; scale 5 , 
$25-49 \%$; scale $7,50-74 \%$; scale $9,>75 \%$. The disease index (DI) was calculated using the following equation:

$$
\mathrm{DI}(\%)=\frac{A \times 0+B \times 1+C \times 3+D \times 5+E \times 7+F \times 9}{N \times 9} \times 100
$$

where $A-F$ are the number of leaves with scales of $0,1,3,5,7$, and 9 , respectively. $N$ indicates the total number of leaves.

\subsection{Statistical Analysis}

The experiments were repeated at least three times. Excel 2016 and GraphPad Prism version 9.2.0 (332) software were used for statistical analysis and figure preparation. Results are expressed as mean \pm standard deviation (SD) or standard error (SE). Differences among means were tested for statistical significance using one-way analysis of variance (ANOVA), followed by Tukey's multiple tests. Statistical significance was set at $p<0.05$.

\section{Results}

3.1. Effects of A. conyzoides Ethanol Extract (ACE) on the Mycelial Growth of P. oryzae and R. solani

We assayed the antifungal activity of ACE against P. oryzae and R. solani. After culturing on agar media containing various concentrations of ACE, the radial mycelial growth was measured, and the PI (\%) was calculated. The results shown in Figure 1 indicate that ACE significantly suppressed the growth of P. oryzae and R. solani in a dose-dependent manner. We could roughly estimate the $\mathrm{IC}_{50}$ of $\mathrm{ACE}$ to be $250-275 \mu \mathrm{g} / \mathrm{mL}$ against $P$. oryzae and $400-450 \mu \mathrm{g} / \mathrm{mL}$ against $R$. solani.
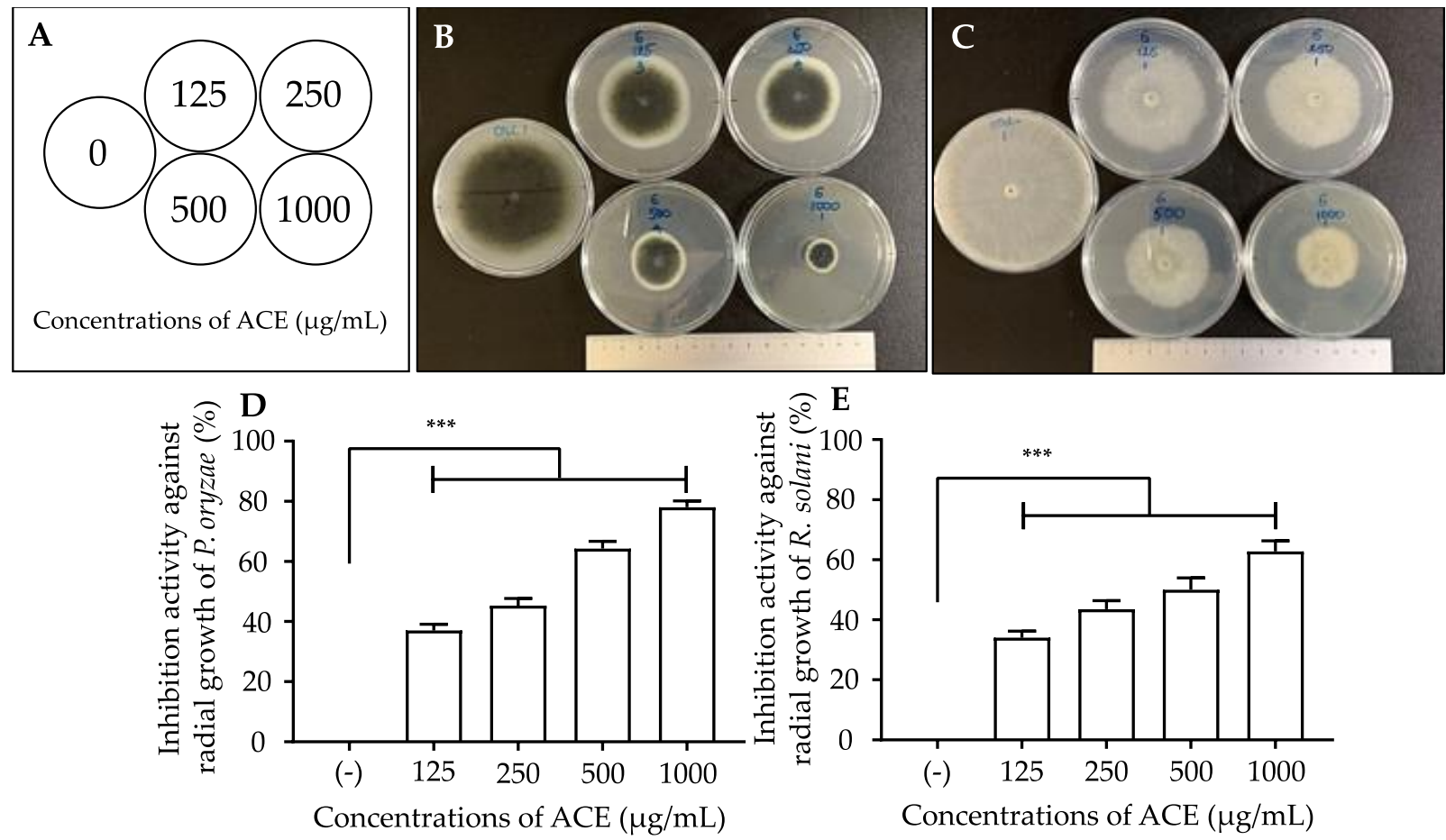

Figure 1. Inhibitory activities of ACE against mycelial growth of P. oryzae (B,D) and R. solani (C,E). P. oryzae and R. solani were inoculated on PDA plates containing different concentrations of ACE shown in (A). After incubation at $26^{\circ} \mathrm{C}$ for 14 days (P. oryzae) or 2 days (R. solani), the diameters of mycelial growth area of fungi were measured in $\mathrm{mm}$, and PI (\%) was calculated $(\mathbf{D}, \mathbf{E}) . n=5$; data are presented as mean $\pm \mathrm{SD} ;{ }^{* * *}, p<0.001$. 


\subsection{Isolation of Antifungal Compounds from $A C E$}

To isolate antifungal compounds, ACE was separated via solvent partition into four fractions: ACE-hexane, ACE-chloroform, ACE-EtOAc, and ACE-water. After drying by evaporation and subsequent lyophilization, the fractions were assayed for antifungal activity against $P$. oryzae and $R$. solani. As shown in Figure 2, the ACE-EtOAc and ACE-water fractions did not inhibit fungal growth $(p>0.05)$. In contrast, ACE-hexane significantly suppressed the growth of both fungi and exhibited PI values of $29 \%, 44 \%$, and $54 \%$ against P. oryzae, and $34 \%, 48 \%$, and $57 \%$ against $R$. solan $(p<0.001)$ at 125,250 , and $500 \mu \mathrm{g} / \mathrm{mL}$, respectively. Compared to ACE-hexane, ACE-chloroform showed a slightly lower antifungal activity against $P$. oryzae $(23 \%$ at $125 \mu \mathrm{g} / \mathrm{mL})$, but much lower activity against $R$. solani $(10 \%$ at $250 \mu \mathrm{g} / \mathrm{mL})$. Thus, ACE-hexane and ACE-chloroform were separated for further analysis.

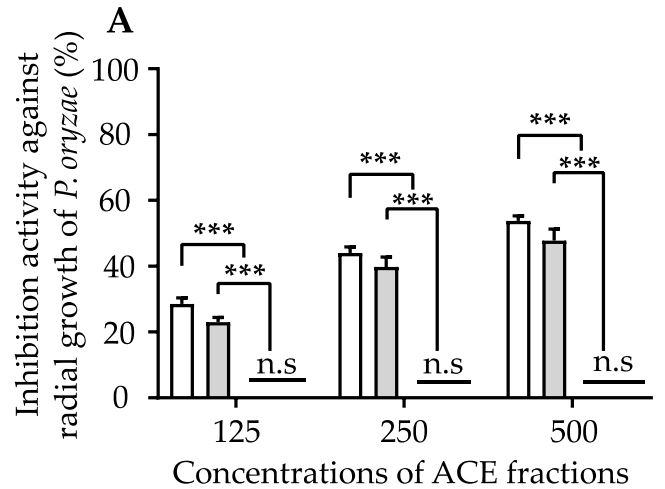

$(\mu \mathrm{g} / \mathrm{mL})$

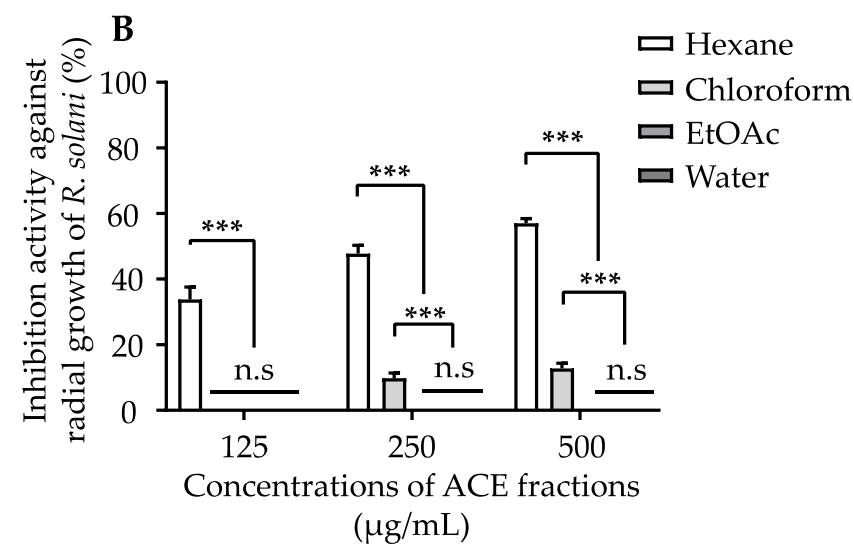

Figure 2. Antifungal activities of ACE fractions obtained via solvent partition. Four fractions, ACE-hexane, ACE-chloroform, ACE-EtOAc, and ACE-water, were assayed for their antifungal activities against P. oryzae (A) and R. solani (B) using the poisoned food assay. After culturing P. oryzae for 14 days or $R$. solani for 2 days, radial growth of fungi was measured and PI (\%) was calculated. $n=5$, n.s., no significant difference; data are presented as mean $\pm \mathrm{SD} ;{ }^{* * *}, p<0.001$.

ACE-hexane and ACE-chloroform were separated using silica gel chromatography and reversed-phase chromatography. Four antifungal compounds (1-4) were isolated from ACE-hexane, and one compound (5) was isolated from ACE-chloroform.

\subsection{Identification of Antifungal Compounds}

The structures of the isolated antifungal compounds were determined using a combination of ESI-TOF MS and one- and two-dimensional NMR spectroscopy, after verifying their purities using TLC. The spectroscopic data for all the compounds are summarized in the Supporting Information, and the elucidated structures are shown in Figure 3. The ESI-TOF-MS of compound 1 gave a positive of $[\mathrm{M}+\mathrm{H}]]^{+}$at $m / z 221$, and the ${ }^{1} \mathrm{H}$ and ${ }^{13} \mathrm{C}$ NMR spectra showed a chromene moiety with two methoxy groups at 3.66 and $3.69 \mathrm{ppm}$ and two methyl groups whose equivalent chemical shift was 1.32 ppm (Supplementary Table S1, Figures $\mathrm{S} 1$ and S2). Based on the spectroscopic data, compound $\mathbf{1}$ was assigned to precocene II (molecular weight $=220, \mathrm{C}_{13} \mathrm{H}_{16} \mathrm{O}_{3}$ ), 6, 7-dimethoxy-2,2-dimethyl-2H-chromene. The mass and NMR data were identical to those reported in a previous report [41]. The NMR spectroscopic analysis showed that the others, compounds $2-5$, were polymethoxyflavones, and the ${ }^{1} \mathrm{H}$ signal of position 3 in the $\mathrm{C}$-ring was observed around $6.7 \mathrm{ppm}$ for all compounds 2-5. The positive ESI-TOF MS spectrum of compound 3 showed peaks at $m / z 403[\mathrm{M}+\mathrm{H}]^{+}$ and $425[\mathrm{M}+\mathrm{Na}]^{+}$, and the molecular weight and formula were determined to be 402 and $\mathrm{C}_{21} \mathrm{H}_{22} \mathrm{O}_{8}$, respectively. The ${ }^{1} \mathrm{H}$ and ${ }^{13} \mathrm{C}$ NMR spectra showed that compound 3 contained a flavone moiety with six methoxy groups (Table S3, Figures S5-S8). Three aromatic signals observed at $7.13 \mathrm{ppm}$ (doublet, $1 \mathrm{H}$ ), $7.54 \mathrm{ppm}$ (doublet, $1 \mathrm{H}$ ), and $7.66 \mathrm{ppm}$ (double doublet, $1 \mathrm{H}$ ) indicate that the B-ring of compound 3 is a catechol moiety. Based on the analysis of 
${ }^{1} \mathrm{H}-{ }^{13} \mathrm{C}$ HSQC and HMBC spectroscopy, the hydroxyl groups at 5, 6, 7, and 8 of the A-ring and $3^{\prime}$ and $4^{\prime}$ of the B-ring were methylated, indicating that compound 3 was nobiletin (5,6,7,8,3' , $^{\prime}$-hexamethoxyflavone) and 2-(3,4-dimethoxyphenyl)-5,6,7,8-tetramethoxy-4H-1benzopyran-4-one. The ${ }^{1} \mathrm{H}$ NMR spectra of compounds 2 and 4 showed a singlet peak with an integral of $2 \mathrm{H}$ in the range $7.2-7.3 \mathrm{ppm}$, indicating that both contain a pyrogallol moiety in the B-ring. The number of methoxy signals in the range of 3.8-4.1 ppm indicated that compounds $\mathbf{2}$ and $\mathbf{4}$ contain seven and six methoxy groups, respectively. Compared to compound 3 , nobiletin, compound 2 (molecular weight $=432, \mathrm{C}_{22} \mathrm{H}_{24} \mathrm{O}_{9}$ ) was determined to be $5^{\prime}$-methoxynobiletin $\left(5,6,7,8,3^{\prime}, 4^{\prime}, 5^{\prime}\right.$-heptamethoxyflavone), 2-(3,4,5-trimethoxyphenyl)5,6,7,8-tetramethoxy-4H-1-benzopyran-4-one (Table S2, Figures S3 and S4). Compound 4 showed another singlet peak at $7.15 \mathrm{ppm}$ in the aromatic region, which was determined to position 8 in the A-ring by the ${ }^{1} \mathrm{H}-{ }^{13} \mathrm{C}$ connection of the $\mathrm{HMBC}$ spectrum (Table S4, Figures S9-S12). Consequently, compound 4 (molecular weight $=402, \mathrm{C}_{21} \mathrm{H}_{22} \mathrm{O}_{8}$ ) was assigned to 5,6,7,3', $4^{\prime}, 5^{\prime}$-hexamethoxyflavone, 2-(3,4,5-trimethoxyphenyl)-5,6,7-trimethoxy4H-1-benzopyran-4-one. In the ${ }^{1} \mathrm{H}$ NMR spectrum of compound 5 , a singlet peak with an integral of $2 \mathrm{H}$ was observed at $6.09 \mathrm{ppm}$, which is a typical chemical shift of a methylenedioxy group in the aromatic group (Table S5, Figures S13-S15). The chemical shifts of H2' at $7.16 \mathrm{ppm}$ and $\mathrm{H}^{\prime}$ at 7.11 were slightly different, which also supports that a methoxy and methylenedioxy group exists in the B-ring. The ${ }^{1} \mathrm{H}$ NMR spectrum of compound 5 showed five methoxy groups, and the ${ }^{1} \mathrm{H}^{13} \mathrm{C}$ HSQC and HMBC spectra revealed that compound 5 (molecular weight $=416, \mathrm{C}_{21} \mathrm{H}_{20} \mathrm{O}_{9}$ ) contained four methoxy groups in the A-ring and a methoxy and methylenedioxy group in the B-ring, resulting in eupalestin (5,6,7,8,3'-pentamethoxy-4' ' $^{\prime}$-methylenedioxyflavone), 2-(7-methoxy-1,3-benzodioxol-5yl)-5,6,7,8-tetramethoxy-4H-1-benzopyran-4-one. All values of the molecular weight were confirmed by ESI-TOF-MS spectroscopy, and the NMR data were identical to those reported in the literature [42-45].<smiles>COc1ccc(-c2cc(=O)c3c(OC)c(OC)c(OC)c(OC)c3oc2=O)cc1OC</smiles>

Figure 3. Chemical structures of antifungal compounds 1-5 isolated from ACE. The chemical structures of the compounds were determined using ESI-TOF MS and NMR spectroscopy. Compound 1, precocene II; compound 2, $5^{\prime}$-methoxynobiletin; compound 3, nobiletin; compound 4, 5,6,7,3', $4^{\prime}, 5^{\prime}$ hexamethoxyflavone; compound 5 , eupalestin.

\subsection{Antifungal Activities of Isolated Compounds against P. oryzae and R. solani}

The antifungal activities of compounds $\mathbf{1}-\mathbf{5}$ were assayed against $P$. oryzae and $R$. solani. The $\mathrm{IC}_{50}$ values, which are the concentrations required for suppressing $P$. oryzae and $R$. solani growth by $50 \%$, were calculated from Figures 4 and 5 and are summarized in Table 1 . Com- 
pounds 1-4 isolated from the hexane fraction suppressed mycelial growth of both fungi in a dose-dependent manner. The $\mathrm{IC}_{50}$ values indicated that compound $\mathbf{1}$ possessed the strongest antifungal activity against both fungi to the same degree. Compounds $\mathbf{2}$ and $\mathbf{3}$ showed the highest antifungal efficacy among the five compounds and suppressed the growth of $P$. oryzae more strongly than that of $R$. solani. Compound 4 showed weaker antifungal activity, and its activity against $R$. solani was stronger than that against $P$. oryzae. Compound 5, isolated from the chloroform fraction, inhibited only P. oryzae growth, but its efficacy was low.
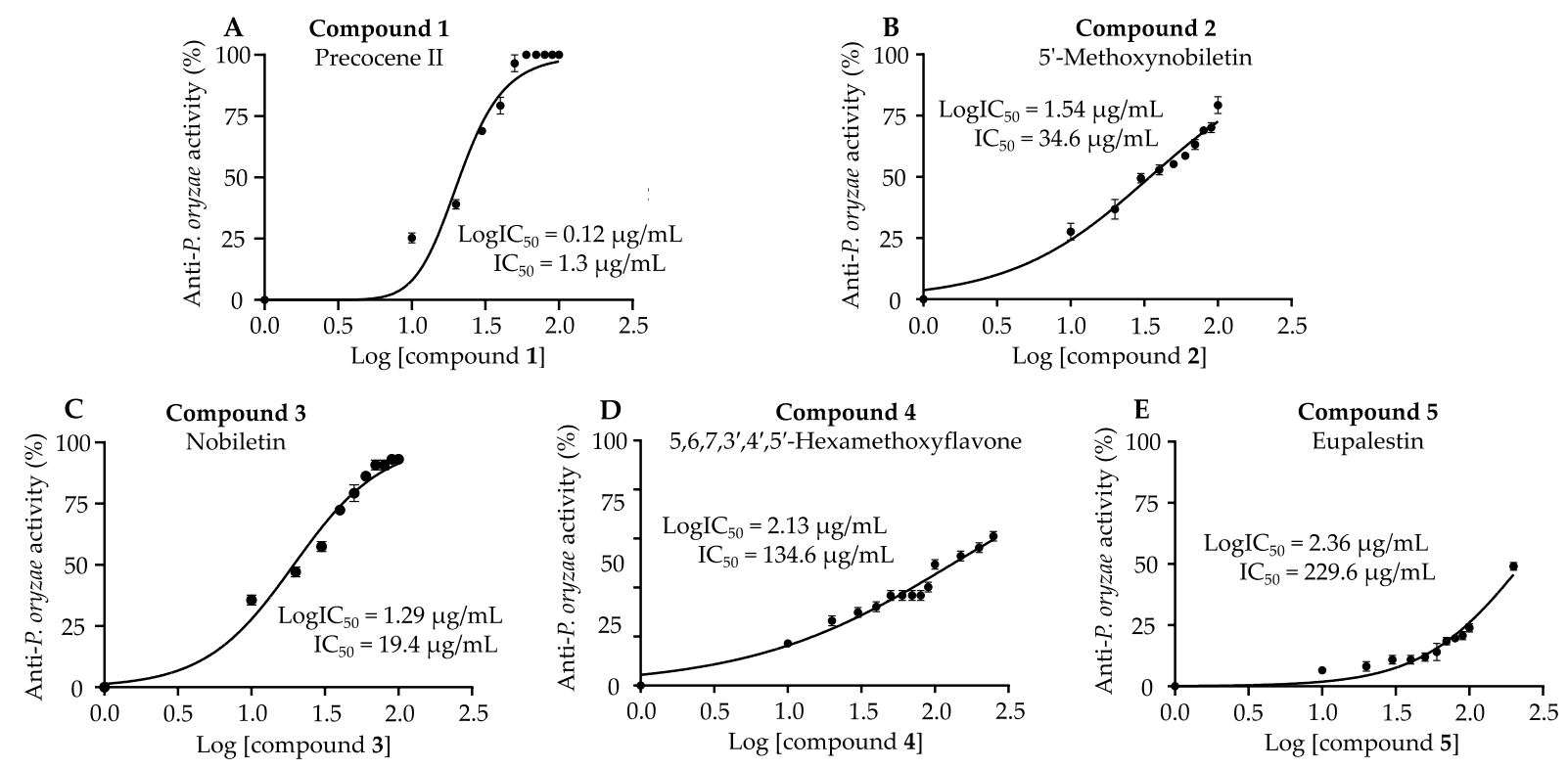

Figure 4. Antifungal activities of isolated compounds 1-5 (A-E) against the development of P. oryzae. P. oryzae was cultured for 7 days on PDA plates containing different concentrations of each compound in the range of $10-250 \mu \mathrm{g} / \mathrm{mL}$. Then, the diameters of mycelial growth area of fungi were measured and $\mathrm{IC}_{50}$ values were calculated. PI (\%) calculated was plotted vs logarithmic concentration of the compound. $n=3$.
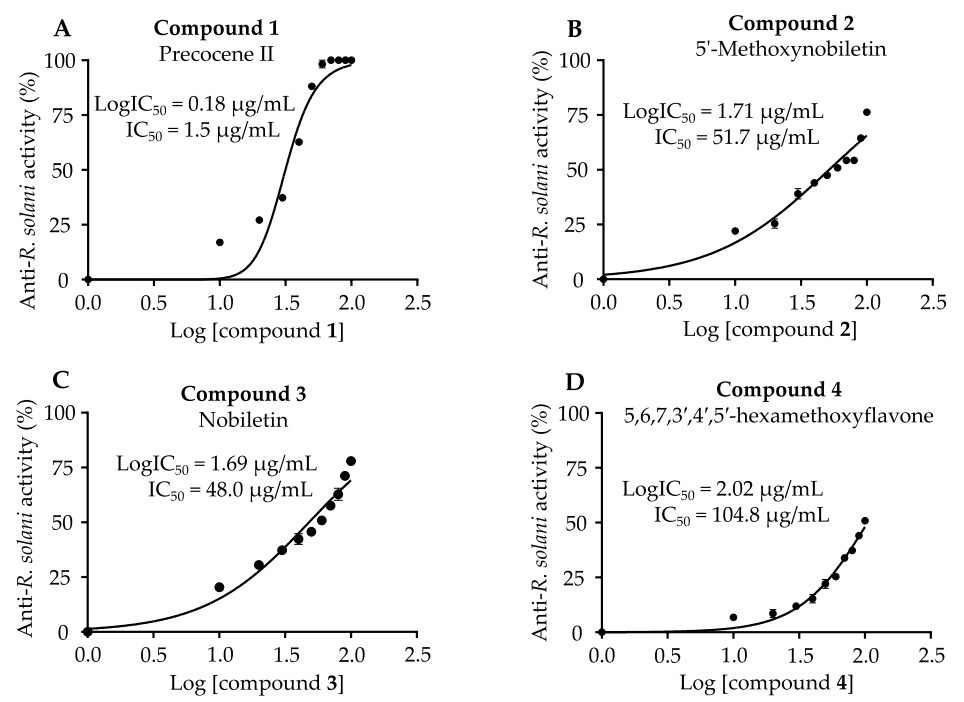

Figure 5. Antifungal activities of isolated compounds 1-5 (A-D) against the development of R. solani. R. solani was cultured for 1 day on PDA plates containing different concentrations of each compound from 10 to $250 \mu \mathrm{g} / \mathrm{mL}$. Then, the diameters of mycelial growth area of fungi were measured and $\mathrm{IC}_{50}$ values were calculated. PI (\%) calculated was plotted vs logarithmic concentration of the compound. $n=3$. 
Table 1. Antifungal activities against P. oryzae and R. solani of compounds 1-5. Based on the results shown in Figures 4 and 5, $\mathrm{IC}_{50}$ values were calculated and expressed as mean \pm SE. N.D. indicates that activity was not detected in the range of $10-250 \mu \mathrm{g} / \mathrm{mL}$.

\begin{tabular}{ccc}
\hline \multirow{2}{*}{ Compounds } & \multicolumn{2}{c}{$\mathrm{IC}_{\mathbf{5 0}}(\boldsymbol{\mu g} / \mathrm{mL})$} \\
\cline { 2 - 3 } & Anti-P. oryzae & Anti-R. solani \\
\hline 1. Precocene II & $1.3 \pm 0.02$ & $1.5 \pm 0.2$ \\
\hline 2. 5 $^{\prime}$-Methoxynobiletin & $34.6 \pm 1.5$ & $51.7 \pm 1.7$ \\
\hline 3. Nobiletin & $19.4 \pm 1.3$ & $48.0 \pm 1.5$ \\
\hline 4. 5,6,7,3' ( $^{\prime}, 5^{\prime}$-Hexamethoxyflavone & $134.6 \pm 2.1$ & $104.8 \pm 2.0$ \\
\hline 5. Eupalestin & $229.6 \pm 2.3$ & N.D. \\
\hline
\end{tabular}

\subsection{Field Trial Test for Protective Effect of ACE on Rice Crop against P. oryzae Infection}

To assay the effect of ACE on the infection of rice with P. oryzae in a shaded nethouse, we sprayed $0.2 \%$ DMSO (negative control), ACE, or tricyclazole (commercially available fungicide, positive control) at 2 days after inoculation with P. oryzae. The negative control (Figure 6A) showed distinct symptoms of blast disease after treatment for 15 days, while rice plants sprayed with ACE (Figure 6B) or tricyclazole (Figure 6C) showed fewer symptoms and seemed to be healthier. At 5, 10, and 15 days of treatment, the disease indices (\%) of the ACE-treatment and tricyclazole groups were significantly smaller than those of the negative control group (Figure 6D). Compared with the negative control, at 10 and 15 days after treatment, $2 \mathrm{mg} / \mathrm{mL}$ of ACE suppressed the infection by $57.1 \%$ and $55.5 \%$, and $0.625 \mathrm{mg} / \mathrm{mL}$ of tricyclazole suppressed the infection by $64.1 \%$ and $63.8 \%$, respectively. These effects of ACE and tricyclazole treatments showed no significant differences, confirming the protective effect of $\mathrm{ACE}$ on rice from blast disease.

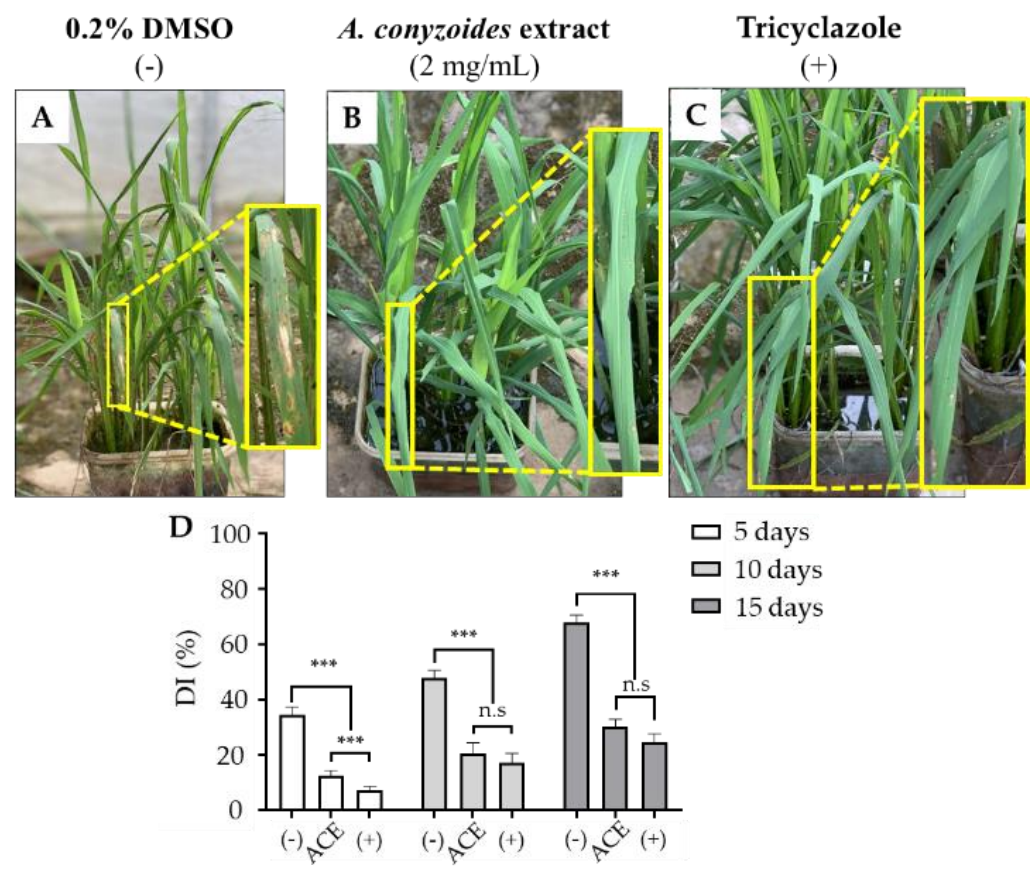

Figure 6. Effects of ACE on blast disease of rice. Rice plants were inoculated with P. oryzae, and subsequently sprayed with $0.2 \%$ DMSO (A), ACE (B), or tricyclazole (C). Images are representatives of rice after 15 days' treatment and include higher magnifications of the boxed regions shown in the left panels (A-C). Disease levels were expressed as DI (\%) at 5, 10, and 15 days after treatments (D). ACE, ACE-treatment; -, 0.2\% DMSO treatment (negative control); + , tricyclazole treatment (positive control); ${ }^{* * *}, p<0.001$. 


\section{Discussion}

Control of the rice fungal diseases, blast diseases, and sheath blight diseases caused by $P$. oryzae and $R$. solani, respectively, is immensely important because of their widespread distribution and destructive properties $[5,7,8]$. To suppress the generation of fungicideresistant fungi and develop eco-friendly fungicides, we sought antifungal compounds of biological origin. Accordingly, we screened the natural antifungal activities of various herbs and found $A$. conyzoides as an alternative to synthetic fungicides against the growth of $P$. oryzae and R. solani (Figure 1). A previous study reported that organic solvent and aqueous extracts of $A$. conyzoides significantly reduced the biomass of Fusarium solani, which could be used for the management of wilt disease [46]. Therefore, we focused on evaluating the effect of antifungal compounds from ACE against the growth of P. oryzae and R. solani and conducted a field trial test to demonstrate the protective effect of ACE against blast disease in rice plants. In particular, ACE-hexane and ACE-chloroform fractions significantly inhibited the growth of both fungi compared with the other fractions and were further used to isolate the active compound (Figure 2). Notably, ACE inhibited the growth of $P$. oryzae under shaded net-house conditions, indicating that ACE or its active components are potential antifungal agents that can protect rice from blast disease (Figure 6).

In this study, we used a poisoned food assay to screen and isolate antifungal compounds. In the future, studies can take advantage of high-throughput methods, such as a combination of analytical-scale microfractionation with a microplate-based assay [20]. However, we isolated and identified five compounds, which had a notable activity to suppress the mycelial growth of P. oryzae and R. solani (Figures 4 and 5). Among them, precocene II (compound 1) isolated from A. conyzoides has been reported to exhibit antifungal activity against R. solani, Sclerotium rolfsii [47], and Aspergillus flavus [48]. Nobiletin (compound 3) from citrus has antifungal activity against Penicillium digitatum and Alternaria alternate with an $\mathrm{IC}_{50}$ of 1.62 and $0.28 \mathrm{mM}$, respectively [49]. In addition, $5^{\prime}$-methoxynobiletin (compound 2) and eupalestin (compound 5) were reported to have insecticidal activities in a previous study, but only compound $\mathbf{2}$ showed this ability against Diaphania hyalinata and Rhyzopertha dominica [50]. In a study on allelochemicals released by A. conyzoides to control weeds and soil pathogenic fungi in citrus orchards, $5^{\prime}$-methoxynobiletin (compound 2) and $5,6,7,3^{\prime}, 4^{\prime}, 5^{\prime}$-hexamethoxyflavone (compound 4) significantly inhibited the growth of weeds and spore germination of the soil pathogenic fungi Phytophthora citrophthora, Pythium aphanidermatum, and Fusarium solani [51]. Moreover, our results showed that $5^{\prime}$-methoxynobiletin (compound 2) and nobiletin (compound 3), both of which possess a methoxy group at the 8-position, have higher antifungal activities than 5,6,7,3' $4^{\prime}, 5^{\prime}$-hexamethoxyflavone (compound 4). In addition, the presence of a methylenedioxy group at the $4^{\prime}, 5^{\prime}$-position of eupalestin (compound 5) reduced activity compared to compounds 2 and 3 . Nobiletin (compound 3) showed higher activity than 5,6,7,3', $4^{\prime}, 5^{\prime}$-hexamethoxyflavone (compound 4), although both flavones have six methoxy groups. This suggests that methylation at the 8-position is important for antifungal activity. It has been pointed out that the fully methylated flavones in the A-ring increased the protection against fungi because these compounds easily penetrate membranes, affecting the permeability of cytomembrane [52-54]. This could explain why all flavones isolated as antifungal agents were polymethoxylated.

Previous studies have shown that jasmonic acid and hydroxybenzoic acid from the leaves of Oryza officinalis and gingerenones A, B, and C and isogingerenone B from Zingiber officinale suppress the growth of $P$. oryzae in rice blast disease. In addition, sanguinarine isolated from Sanguinaria, Macleaya cordata, and Canadensis (Papaveraceae) has been reported to be effective against $R$. solani by systemic acquired resistance (SAR)-mediated accumulation of endogenous phenolics [55]. It has been reported that antifungal compounds isolated from $A$. conyzoides are effective against certain strains either by eradicating the fungal cell directly or by precluding cell growth. Remarkably, these compounds can also interfere with the competent discharge of mycotoxins in combination. Previous studies demonstrated that precocene II exhibited its activity by stopping the release of mycotoxins as aflatoxins and trichothecenes [56]. Wu et al. showed that the fraction containing 
polymethoxyflavones from Citrus reticulata suppressed Aspergillus niger by altering the permeability of the cytomembrane and impairing the integrity of cell walls via inhibition of chitin production [52]. The alteration of membrane permeability by polymethoxyflavones may be caused by their penetration into the membrane [52-54]. In general, the action mechanisms of synthetic fungicides include inhibition of sterol synthesis, inhibition of mitochondrial electron transport (inhibition of respiration), inhibition of multi-site enzymes, inhibition of nucleic acid and protein synthesis, and so on [57]. The study by Wu et al. suggested that polymethoxyflavones have a similar effect on fungi to synthetic fungicides, which disrupt the integrity of the cell membrane by inhibiting sterol synthesis, although the mechanism for increasing membrane permeability may be different. These results suggest that $\mathrm{ACE}$ and its antifungal compounds may have the same antifungal mechanism as reported by Wu et al.; however, further research on antifungal mechanisms is necessary for developing novel antifungals for field use, especially in rice blast disease.

In this study, we examined the effect of ACE on the development of blast disease in rice infected with Pyricularia oryzae in a shaded net-house. Kamboj and Saluja reported that extracts of Azadirachta indica suppressed the development and spread of blast disease in rice plants in the greenhouse, and the rice treated for 20 days with ethanol leaf extract and oil extract of $A$. indica seeds showed disease severity (\%) of 50\% and $75 \%$, respectively [26]. Our results demonstrated that ACE-treatment suppressed blast disease to $55.5 \%$ at 15 days by the index of damaged area (\%) of the leaf, suggesting that the suppressive effects of both plant extracts were almost the same. We also demonstrated that the suppressive effect of treatment with ACE $(2 \mathrm{mg} / \mathrm{mL})$ was equivalent to that of tricyclazole $(0.625 \mathrm{mg} / \mathrm{mL})$. Thus, we confirmed the protective effect of ACE against blast disease in rice in vivo.

To suppress the generation of fungicide-resistant fungi, antifungals with different mechanisms of action should be combined. ACE contains at least two different types of antifungals, polymethoxyflavones and precocene II, suggesting that $\mathrm{ACE}$ is a natural cocktail of antifungals with similar ability to the commercial product tricyclazole. Taken together with the results of the field trial test, ACE represents a promising antifungal alternative against blast disease and sheath blight disease in rice.

\section{Conclusions}

We isolated and identified five antifungal compounds from the aerial parts of Ageratum conyzoides L. Among them, three polymethoxyflavones, $5^{\prime}$-methoxynobiletin (compound 2), nobiletin (compound 3), and 5,6,7,3', $4^{\prime}, 5^{\prime}$-hexamethoxyflavone (compound 4) inhibited the growth of P. oryzae and R. solani in vitro, whereas eupalestin (compound 5) was only found in P. oryzae. In addition, precocene II, which has a different structure, showed strong antifungal activity against both fungi with a ten-fold smaller $\mathrm{IC}_{50}$. Furthermore, we demonstrated the protective effect of the ethanolic extract on rice from blast disease by field trial tests in a shaded net-house. Taken together, the extract from A. conyzoides $\mathrm{L}$. represents a promising antifungal agent against fungal disease in the field. This study will provide basic information for the development of natural fungicides as alternative agents for synthetic agents.

Supplementary Materials: The following are available online at https: / www.mdpi.com/article/ 10.3390/agriculture11111169/s1, Table S1: NMR data of compound 1, Precocene II, Figure S1: ${ }^{1} \mathrm{H}$ NMR spectrum of compound 1 recorded in DMSO- $d_{6}$, Figure S2: ${ }^{13} \mathrm{C}$ NMR spectrum of compound 1 recorded in DMSO- $d_{6}$; Table S2: NMR data of compound 2, $5^{\prime}$-Methoxynobeletin, Figure S3: ${ }^{1} \mathrm{H}$ NMR spectrum of compound 2 recorded in MeOD- $d_{4}$, Figure S4: ${ }^{13} \mathrm{C}$ NMR spectrum of compound 2 recorded in MeOD- $d_{4}$; Table S3: NMR data of compound 3, Nobiletin, Figure S5: ${ }^{1} \mathrm{H}$ NMR spectrum of compound 3 recorded in MeOD- $d_{4}$, Figure S6: ${ }^{13} \mathrm{C}$ NMR spectrum of compound 3 recorded in MeOD- $d_{4}$, Figure S7: ${ }^{1} \mathrm{H}-{ }^{13} \mathrm{C}$ HSQC spectrum of compound 3 recorded in MeOD- $d_{4}$, Figure S8: ${ }^{1} \mathrm{H}_{-}{ }^{13} \mathrm{C}$ HMBC spectrum of compound 3 recorded in MeOD- $d_{4}$; Table S4: NMR data of compound $4,3^{\prime}, 4^{\prime}, 5^{\prime}, 5,6,7-$ Hexamethoxyflavone, Figure S9: ${ }^{1} \mathrm{H}$ NMR spectrum of compound 4 recorded in MeOD- $d_{4}$, Fiigure S10: ${ }^{13} \mathrm{C}$ NMR spectrum of compound 4 recorded in MeOD- $d_{4}$, Figure S11: ${ }^{1} \mathrm{H}_{-}{ }^{13} \mathrm{C}$ HSQC spectrum of compound 4 recorded in MeOD- $d_{4}$, Figure S12: ${ }^{1} \mathrm{H}^{13} \mathrm{C}$ HMBC spectrum of 
compound 4 recorded in MeOD- $d_{4}$; Table S5: NMR data of compound 5, Eupalestin, Figure S13: ${ }^{1} \mathrm{H}$ NMR spectrum of compound 5 recorded in $\mathrm{CDCl}_{3}$, Figure S14: ${ }^{1} \mathrm{H}_{-}{ }^{13} \mathrm{C}$ HSQC spectrum of compound 5 recorded in $\mathrm{CDCl}_{3}$, Figure S15: ${ }^{1} \mathrm{H}_{-}{ }^{13} \mathrm{C} \mathrm{HMBC}$ spectrum of compound 5 recorded in $\mathrm{CDCl}_{3}$.

Author Contributions: Conceptualization, K.K. (Kaeko Kamei), C.C.N. and L.V.V.; methodology, K.K. (Kaeko Kamei) and C.C.N.; validation, C.C.N., K.K. (Kenji Kanaori), T.Q.C.N., K.K. (Kaeko Kamei), T.D.B., X.H.T.D. and L.V.V.; formal analysis, C.C.N., T.D.B. and K.K. (Kaeko Kamei); Silica gel Chromatography and HPLC, C.C.N. and K.K. (Kaeko Kamei); NMR, T.Q.C.N. and K.K. (Kaeko Kamei); investigation, C.C.N. and X.H.T.D.; resources, K.K. (Kenji Kanaori), C.C.N. and K.K. (Kaeko Kamei); writing-original draft preparation, C.C.N. and K.K. (Kaeko Kamei); writing-review and editing, C.C.N., T.Q.C.N., K.K. (Kenji Kanaori), T.D.B., X.H.T.D., L.V.V. and K.K. (Kaeko Kamei); visualization, K.K. (Kaeko Kamei), C.C.N., T.D.B., T.Q.C.N., K.K. (Kenji Kanaori) and L.V.V.; supervision, K.K. (Kaeko Kamei); project administration, K.K. (Kaeko Kamei) and C.C.N. All authors read and agreed to the published version of the manuscript.

Funding: This study was funded in part by the Can Tho University Improvement Project VN14-P6, supported by a Japanese ODA loan.

Institutional Review Board Statement: Not applicable.

Data Availability Statement: All the raw data are available and provided upon request.

Acknowledgments: We are grateful to Tran Vu Phen at the Department of Plant Protection of Can Tho University, Vietnam, for identifying Ageratum conyzoides L. Finally, we thank the Department of Plant Protection of the Cuu Long Delta Rice Research Institute (CLDRRI), Vietnam, for providing the Pyricularia oryzae and Jasmine 85 cultivar.

Conflicts of Interest: The authors declare no conflict of interest.

\section{References}

1. Li, N.; Xu, R.; Duan, P.; Li, Y. Control of grain size in rice. Plant Reprod. 2018, 31, 237-251. [CrossRef] [PubMed]

2. Gross, B.L.; Zhao, Z. Archaeological and genetic insights into the origins of domesticated rice. Proc. Natl. Acad. Sci. USA 2014, 111, 6190-6197. [CrossRef] [PubMed]

3. Fukagawa, N.K.; Ziska, L.H. Rice: Importance for global nutrition. J. Nutr. Sci. Vitaminol. 2019, 65, S2-S3. [CrossRef] [PubMed]

4. Muthayya, S.; Sugimoto, J.D.; Montgomery, S.; Maberly, G.F. An overview of global rice production, supply, trade, and consumption. Ann. N. Y. Acad. Sci. 2014, 1324, 7-14. [CrossRef]

5. Ou, S.H. Rice Diseases, 2nd ed.; Commonwealth Mycological Institute: Egham, UK, 1985; ISBN 0-85198-545-9.

6. Jiang, N.; Yan, J.; Liang, Y.; Shi, Y.; He, Z.; Wu, Y.; Zeng, Q.; Liu, X.; Peng, J. Resistance Genes and their Interactions with Bacterial Blight/Leaf Streak Pathogens (Xanthomonas oryzae) in Rice (Oryza sativa L.)—An Updated Review. Rice 2020, 13, 3. [CrossRef] [PubMed]

7. Groth, D.E. Rice Diseases and Disorders in Louisiana; LSU Agricultural Experiment Station Reports; LSU Agricultural Center: Baton Rouge, LA, USA, 1991.

8. Shahriar, S.A.; Imtiaz, A.A.; Hossain, M.B.; Husna, A.; Eaty, M.N.K. Review: Rice Blast Disease. Annu. Res. Rev. Biol. 2020, 35, 50-64. [CrossRef]

9. Asibi, A.E.; Chai, Q.; Coulter, J.A. Rice blast: A disease with implications for global food security. Agronomy 2019, 9, 451. [CrossRef]

10. Ashik Iqbal Khan, M.; Rejwan Bhuiyan, M.; Hossain, M.S.; Pratim Sen, P.; Ara, A.; Abubakar Siddique, M.; Ansar Ali, M. Neck blast disease influences grain yield and quality traits of aromatic rice. Comptes Rendus Biol. 2014, 337, 635-641. [CrossRef]

11. Law, J.W.F.; Ser, H.L.; Khan, T.M.; Chuah, L.H.; Pusparajah, P.; Chan, K.G.; Goh, B.H.; Lee, L.H. The potential of streptomyces as biocontrol agents against the rice blast fungus, Magnaporthe oryzae (Pyricularia oryzae). Front. Microbiol. 2017, 8, 3. [CrossRef]

12. Xia, Y.; Fei, B.; He, J.; Zhou, M.; Zhang, D.; Pan, L.; Li, S.; Liang, Y.; Wang, L.; Zhu, J.; et al. Transcriptome analysis reveals the host selection fitness mechanisms of the Rhizoctonia solani AG1IA pathogen. Sci. Rep. 2017, 7, 10120. [CrossRef]

13. Anderson, J.P.; Sperschneider, J.; Win, J.; Kidd, B.; Yoshida, K.; Hane, J.; Saunders, D.G.O.; Singh, K.B. Comparative secretome analysis of Rhizoctonia solani isolates with different host ranges reveals unique secretomes and cell death inducing effectors. Sci. Rep. 2017, 7, 10410. [CrossRef]

14. Savary, S.; Willocquet, L.; Elazegui, F.A.; Castilla, N.P.; Teng, P.S. Rice pest constraints in tropical Asia: Quantification of yield losses due to rice pests in a range of production situations. Plant Dis. 2000, 84, 357-369. [CrossRef]

15. Jamali, H.; Sharma, A.; Roohi; Srivastava, A.K. Biocontrol potential of Bacillus subtilis RH5 against sheath blight of rice caused by Rhizoctonia solani. J. Basic Microbiol. 2020, 60, 268-280. [CrossRef] [PubMed]

16. Jiang, H.; Li, Z.; Liu, J.; Shen, Z.; Gao, G.; Zhang, Q.; He, Y. Development and evaluation of improved lines with broad-spectrum resistance to rice blast using nine resistance genes. Rice 2019, 12, 29. [CrossRef] 
17. Hubert, J.; Mabagala, R.B.; Mamiro, D.P. Efficacy of Selected Plant Extracts against Pyricularia grisea. It is Causal Agent of Rice Blast Disease. Am. J. Plant Sci. 2015, 06, 602-611. [CrossRef]

18. Khoa, N.D.; Thúy, P.T.H.; Thuy, T.T.T.; Collinge, D.B.; Jørgensen, H.J.L. Disease-reducing effect of Chromolaena odorata extract on sheath blight and other rice diseases. Phytopathology 2011, 101, 231-240. [CrossRef]

19. Miller, J.D. Fungi and mycotoxins in grains: Implication for stored products research. J. Stored Prod. Res. 1995, 31, 1-16. [CrossRef]

20. Ardalani, H.; Anam, S.; Kromphardt, K.J.K.; Staerk, D.; Kongstad, K.T. Coupling Microplate-Based Antibacterial Assay with Liquid Chromatography for High-Resolution Growth Inhibition Profiling of Crude Extracts: Validation and Proof-of-Concept Study with Staphylococcus aureus. Molecules 2021, 26, 1550. [CrossRef]

21. Brauer, V.S.; Rezende, C.P.; Pessoni, A.M.; De Paula, R.G.; Rangappa, K.S.; Nayaka, S.C.; Gupta, V.K.; Almeida, F. Antifungal agents in agriculture: Friends and foes of public health. Biomolecules 2019, 9, 521. [CrossRef]

22. Gwinn, K.D. Bioactive Natural Products in Plant Disease Control, 1st ed.; Elsevier B.V.: Amsterdam, The Netherlands, 2018; Volume 56, ISBN 9780444640581.

23. Hao, L.; Wang, Y.; Chen, X.; Zheng, X.; Chen, S.; Li, S.; Zhang, Y.; Xu, Y. Exploring the potential of natural products from mangrove rhizosphere bacteria as biopesticides against plant diseases. Plant Dis. 2019, 103, 2925-2932. [CrossRef]

24. Naqvi, S.A.H.; Umar, U.; Hasnain, A.; Rehman, A.; Perveen, R. Effect of Botanical Extracts: A Potential Biocontrol Agent for Xanthomonas oryzae pv. oryzae, Causing Bacterial Leaf Blight Disease of Rice. Pakistan J. Agric. Res. 2018, 32, 59-72. [CrossRef]

25. Govindappa, M.; Umesha, S.; Lokesh, S. Adhatoda vasica leaf extract induces resistance in rice against bacterial leaf blight disease (Xanthomonas oryzae pv. oryzae). Int. J. Plant Physiol. Biochem. 2011, 3, 6-14.

26. Amadioha, A.C. Controlling rice blast in vitro and in vivo with extracts of Azadirachta indica. Crop Prot. 2000, 19, 287-290. [CrossRef]

27. Okunade, A.L. Ageratum conyzoides L. (Asteraceae). Fitoterapia 2002, 73, 1-16. [CrossRef]

28. Kotta, J.C.; Lestari, A.B.S.; Candrasari, D.S.; Hariono, M. Medicinal Effect, in Silico Bioactivity Prediction, and Pharmaceutical Formulation of Ageratum conyzoides L.: A Review. Scientifica 2020, 2020, 6420909. [CrossRef] [PubMed]

29. Ngo, M.T.; Han, J.W.; Yoon, S.; Bae, S.; Kim, S.Y.; Kim, H.; Choi, G.J. Discovery of new triterpenoid saponins isolated from maesa japonica with antifungal activity against rice blast fungus Magnaporthe oryzae. J. Agric. Food Chem. 2019, 67, 7706-7715. [CrossRef]

30. Lee, Y. Lysimachia foenum-graecum herba extract, a novel biopesticide, inhibits ABC transporter genes and mycelial growth of Magnaporthe oryzae. Plant Pathol. J. 2016, 32, 8-15. [CrossRef]

31. Mehta, V.; Kumar, S. Influence of different plant powders as grain protectants on Sitophilus oryzae (L.) (Coleoptera: Curculionidae) in stored wheat. J. Food Prot. 2020, 83, 2167-2172. [CrossRef]

32. Kamboj, A.; Saluja, A. Ageratum conyzoides L.: A review on its phytochemical and pharmacological profile. Int. J. Green Pharm. 2008, 2, 59. [CrossRef]

33. Ming, L.C. Ageratum conyzoides: A Tropical Source of Medicinal and Agricultural Products. In Perspectives on New Crops and New Uses; ASHS Press: Alexandria, VA, USA, 1999; pp. 469-473.

34. Yang, C.; Hamel, C.; Vujanovic, V.; Gan, Y. Fungicide: Modes of Action and Possible Impact on Nontarget Microorganisms. ISRN Ecol. 2011, 2011, 1-8. [CrossRef]

35. Upadhyay, O.P.; Kumar, K.; Tiwari, R.K. Ethnobotanical study of skin treatment uses of medicinal plants of Bihar. Pharm. Biol. 1998, 36, 167-172. [CrossRef]

36. Chauhan, A.; Rijhwani, S. A comprehensive review on phytochemistry of Ageratum conyzoides Linn. (Goat weed). Int. J. Eng. Technol. Manag. Appl. Sci. 2015, 3, 348-358.

37. Kong, C.; Hu, F.; Xu, X.; Zhang, M.; Liang, W. Volatile allelochemicals in the Ageratum conyzoides intercropped citrus orchard and their effects on mites Amblyseius newsami and Panonychus citri. J. Chem. Ecol. 2005, 31, 2193-2203. [CrossRef]

38. Kong, C.; Hu, F.; Xu, X. Allelopathic potential and chemical constituents of volatiles from Ageratum conyzoides under stress. J. Chem. Ecol. 2002, 28, 1173-1182. [CrossRef] [PubMed]

39. Astiti1, N.P.A.; Suprapta, D.N. Antifungal Activity of Teak (Tectona grandis L. F.) Leaf Extract Against Arthrinium phaeosperum (Corda) M.B. Ellis. The Cause of Wood decay on Albizia falcataria (L.) Fosberg. J. Int. Soc. Southeast Asian Agric. Sci. 2012, 18, 62-69.

40. IRRI. Standard Evaluation System for Rice; International Rice Research Institute: Los Baños, Philippines, 2013; 55p.

41. González, A.G.; Aguiar, Z.E.; Grillo, T.A.; Luis, J.G.; Rivera, A.; Calle, J. Chromenes from Ageratum conyzoides. Phytochemistry 1991, 30, 1137-1139. [CrossRef]

42. Le-Van, N.; Van Cuong Pham, T. Two new flavones from Eupatorium coelestinum. Phytochemistry 1979, 18, 1859-1861. [CrossRef]

43. Nour, A.M.M.; Khalid, S.A.; Kaiser, M.; Brun, R.; Abdalla, W.E.; Schmidt, T.J. The antiprotozoal activity of methylated flavonoids from Ageratum conyzoides L. J. Ethnopharmacol. 2010, 129, 127-130. [CrossRef] [PubMed]

44. Chen, J.; Montanari, A.M.; Widmer, W.W. Two New Polymethoxylated Flavones, a Class of Compounds with Potential Anticancer Activity, Isolated from Cold Pressed Dancy Tangerine Peel Oil Solids. J. Agric. Food Chem. 1997, 45, 364-368. [CrossRef]

45. Chen, C.C.; Chen, Y.P.; Hsu, H.Y.; Chen, Y.L. New Flavones from Bauhinia championii BENTH. Chem. Pharm. Bull. 1984, 32, 166-169. [CrossRef]

46. Javed, S.; Bashir, U. Antifungal activity of different extracts of Ageratum conyzoides for the management of Fusarium solani. Afr. J. Biotechnol. 2012, 11, 11022-11029. [CrossRef]

47. Iqbal, M.C.M.; Jayasinghe, U.L.B.; Herath, H.M.T.B.; Wijesekara, K.B.; Fujimoto, Y. A fungistatic chromene from Ageratum conyzoides. Phytoparasitica 2004, 32, 119-126. [CrossRef] 
48. Esper, R.H.; Gonçalez, E.; Felicio, R.C.; Felicio, J.D. Fungicidal activity and constituents of Ageratum conyzoides essential oil from three regions in São Paulo state, Brazil. Arq. Inst. Biol. 2015, 82, 1-4. [CrossRef]

49. Ortuño, A.; Del Rio, J.A. Role of Citrus Phenolic Compounds in the Resistance Mechanism against Pathogenic Fungi. Tree For. Sci. Biotechnol. 2009, 3, 49-53.

50. Moreira, M.D.; Picanço, M.C.; Barbosa, L.C.A.; Guedes, R.N.C.; Barros, E.C.; Campos, M.R. Compounds from Ageratum conyzoides: Isolation, structural elucidation and insecticidal activity. Pest Manag. Sci. 2007, 63, 615-621. [CrossRef]

51. Kong, C.; Liang, W.; Hu, F.; Xu, X.; Wang, P.; Jiang, Y.; Xing, B. Allelochemicals and their transformations in the Ageratum conyzoides intercropped citrus orchard soils. Plant Soil 2004, 264, 149-157. [CrossRef]

52. Wu, T.; Cheng, D.; He, M.; Pan, S.; Yao, X.; Xu, X. Antifungal action and inhibitory mechanism of polymethoxylated flavones from Citrus reticulata Blanco peel against Aspergillus niger. Food Control 2014, 35, 354-359. [CrossRef]

53. Almada-Ruiz, E.; Martínez-Téllez, M.Á.; Hernández-Álamos, M.M.; Vallejo, S.; Primo-Yúfera, E.; Vargas-Arispuro, I. Fungicidal potential of methoxylated flavones from citrus for in vitro control of Colletotrichum gloeosporioides, causal agent of anthracnose disease in tropical fruits. Pest Manag. Sci. 2003, 59, 1245-1249. [CrossRef]

54. Tomas-Barberán, F.A.; Msonthi, J.D.; Hostettmann, K. Antifungal epicuticular methylated flavonoids from Helichrysum nitens . Phytochemistry 1988, 27, 753-755. [CrossRef]

55. Santra, H.K.; Banerjee, D. Natural Products as Fungicide and Their Role in Crop Protection. In Natural Bioactive Products in Sustainable Agriculture; Singh, J., Yadav, A.N., Eds.; Springer: Singapore, 2020; pp. 131-219. ISBN 978-981-15-3023-4.

56. Chahal, R.; Nanda, A.; Akkol, E.K.; Sobarzo-sánchez, E.; Arya, A.; Kaushik, D.; Dutt, R.; Bhardwaj, R.; Rahman, M.H.; Mittal, V. Ageratum conyzoides L. and its secondary metabolites in the management of different fungal pathogens. Molecules 2021, $26,2933$. [CrossRef]

57. Bioscience Solutions-Indepent Crop Protection R\&D Consulting. Available online: https://biocomm.eu/2017/12/17/fungicidemode-action-labcoat-guide-pesticides-biopesticides / (accessed on 11 November 2021). 